Article

\title{
Ligand Control of ${ }^{59}$ Co Nuclear Spin Relaxation Thermometry
}

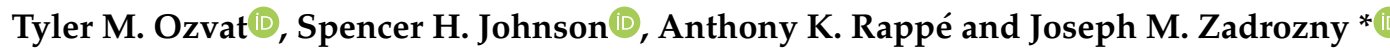 \\ Department of Chemistry, Colorado State University, 1301 Center Ave., Fort Collins, CO 80523-1872, USA; \\ tyler.ozvat@colostate.edu (T.M.O.); spencer.johnson@rams.colostate.edu (S.H.J.); \\ anthony.rappe@colostate.edu (A.K.R.) \\ * Correspondence: joe.zadrozny@colostate.edu
}

Received: 23 October 2020; Accepted: 9 November 2020; Published: 12 November 2020

check for updates

\begin{abstract}
Studying the correlation between temperature-driven molecular structure and nuclear spin dynamics is essential to understanding fundamental design principles for thermometric nuclear magnetic resonance spin-based probes. Herein, we study the impact of progressively encapsulating ligands on temperature-dependent ${ }^{59} \mathrm{Co}_{1}$ (spin-lattice) and $T_{2}$ (spin-spin) relaxation times in a set of $\mathrm{Co}(\mathrm{III})$ complexes: $\mathrm{K}_{3}\left[\mathrm{Co}(\mathrm{CN})_{6}\right](\mathbf{1}) ;\left[\mathrm{Co}\left(\mathrm{NH}_{3}\right)_{6}\right] \mathrm{Cl}_{3}(2) ;\left[\mathrm{Co}(\mathrm{en})_{3}\right] \mathrm{Cl}_{3}(3)$, en = ethylenediamine); $\left[\mathrm{Co}(\mathrm{tn})_{3}\right] \mathrm{Cl}_{3}(4), \mathrm{tn}=$ trimethylenediamine); $\left[\mathrm{Co}(\mathrm{tame})_{2}\right] \mathrm{Cl}_{3}(5)$, tame $=$ triaminomethylethane); and $[\mathrm{Co}($ dinosar $)] \mathrm{Cl}_{3}(6)$, dinosar $=$ dinitrosarcophagine). Measurements indicate that ${ }^{59} \mathrm{Co}_{1}$ and $T_{2}$ increase with temperature for 1-6 between 10 and $60{ }^{\circ} \mathrm{C}$, with the greatest $\Delta T_{1} / \Delta T$ and $\Delta T_{2} / \Delta T$ temperature sensitivities found for 4 and 3, 5.3(3) $\% T_{1} /{ }^{\circ} \mathrm{C}$ and $6(1) \% T_{2} /{ }^{\circ} \mathrm{C}$, respectively. Temperature-dependent $T_{2}{ }^{*}$ (dephasing time) analyses were also made, revealing the highest $\Delta T_{2}{ }^{*} / \Delta T$ sensitivities in structures of greatest encapsulation, as high as $4.64 \% T_{2} *{ }^{\circ} \mathrm{C}$ for 6 . Calculations of the temperature-dependent quadrupolar coupling parameter, $\Delta e^{2} q Q / \Delta T$, enable insight into the origins of the relative $\Delta T_{1} / \Delta T$ values. These results suggest tunable quadrupolar coupling interactions as novel design principles for enhancing temperature sensitivity in nuclear spin-based probes.
\end{abstract}

Keywords: cobalt-59 NMR; magnetic relaxation; nuclear spins; quadrupolar interaction

\section{Introduction}

The control of nuclear spin properties by molecular design is an important capability for many applications, spanning from diagnostic bioimaging [1-3] to encoding and processing quantum information [4-7]. A more focused application is designing temperature dependence into nuclear spin properties toward molecular-level thermometry, an essential technique for next-generation treatments of cancer [8-11]. Here, ${ }^{59} \mathrm{Co}$ nuclear spins are an extremely promising platform for detecting changes in temperature, owing to the extreme thermal sensitivity of the metal ion chemical shift [12]. We note that chemical shift is not the only temperature-dependent property of nuclear spins. Indeed, the influence of temperature on nuclear spin relaxation dynamics may provide a practical additional mechanism for thermometry. Importantly, the quadrupolar coupling of the ${ }^{59} \mathrm{Co}$ $\left(I={ }^{7} / 2\right)$ nucleus is exquisitely sensitive to subtle changes in the structure of the coordination shell. Thus, slight temperature-dependent structural changes are expected to drive nuclear spin behaviors by manipulating the quadrupolar coupling interaction, inducing temperature dependence in the ${ }^{59} \mathrm{Co}$ spin-lattice and spin-spin relaxation times, $T_{1}$ and $T_{2}$, respectively. We note that other, more common nuclear spin-based probes, e.g., ${ }^{1} \mathrm{H},{ }^{13} \mathrm{C},{ }^{19} \mathrm{~F}$, and ${ }^{31} \mathrm{P}$, are all $\mathrm{I}=1 / 2$, are not quadrupolar nuclei, and thus do not sense changes in temperature in this manner [13-15].

Owing to the foregoing advantages, we target design strategies to control the temperature sensitivity of ${ }^{59} \mathrm{Co}$ nuclear spin dynamics in encapsulating ligands, which can prevent chemical 
decomposition in vivo, avoiding the release of toxic metal-ions [16-18]. Recent work by us demonstrated that the interconnected structures of encapsulating scaffolds amplify temperature sensitivity for contained ${ }^{59} \mathrm{Co}$ nuclei [19]. Importantly, these studies probed only temperature-driven changes in chemical shift. In contrast, it is unknown to what extent, if any, encapsulation affects the temperature dependence of ${ }^{59} \mathrm{Co}$ nuclear spin relaxation processes.

Herein, we provide the first test of the effect of encapsulation on the thermometric capabilities of the ${ }^{59} \mathrm{Co}$ nuclear spin dynamics in $\mathrm{Co}(\mathrm{III})$ complexes. To do so, we performed variable-temperature ${ }^{59} \mathrm{Co}$ NMR relaxation time experiments, specifically $T_{1}, T_{2}$, and linewidth analysis $\left(T_{2}{ }^{*}\right)$ with a series of six octahedral and pseudo-octahedral cobalt(III) complexes: (Figure 1) $\mathrm{K}_{3}\left[\mathrm{Co}(\mathrm{CN})_{6}\right](\mathbf{1})$; $\left[\mathrm{Co}\left(\mathrm{NH}_{3}\right)_{6}\right] \mathrm{Cl}_{3}(\mathbf{2})$; $\left[\mathrm{Co}(\mathrm{en})_{3}\right] \mathrm{Cl}_{3}(3)$, en = ethylenediamine); $\left[\mathrm{Co}(\mathrm{tn})_{3}\right] \mathrm{Cl}_{3}(4)$, tn = trimethylenediamine); $\left[\mathrm{Co}(\mathrm{tame})_{2}\right] \mathrm{Cl}_{3}(5)$, tame $=$ triaminomethylethane $) ;$ and $[\mathrm{Co}($ dinosar $)] \mathrm{Cl}_{3}(6)$, dinosar $=$ dinitrosarcophagine $)$. This series enables comparison of the temperature-dependent relaxation dynamics of these complexes with (i) molecular symmetry (e.g., from the $O_{\mathrm{h}}$ complexes 1 and 2 to the nearly $D_{3}$ complexes 3-6), and (ii) relative degree of encapsulation (from 2-6). We further computed quadrupolar coupling parameters from computational structures to rationalize the relative temperature dependence of the relaxation dynamics. We find no precise correlation between relaxation and encapsulation. Instead, we propose that $\Delta T_{1} / \Delta T$ of the ${ }^{59} \mathrm{Co}$ nucleus is driven by changes in the quadrupolar coupling parameters, $\Delta e^{2} q Q$, from thermally driven structures. These evaluations highlight important structural conditions of chelation among the series, which are shown to yield various trends in temperature-dependent $T_{1}, T_{2}$, and $T_{2}{ }^{*}$.

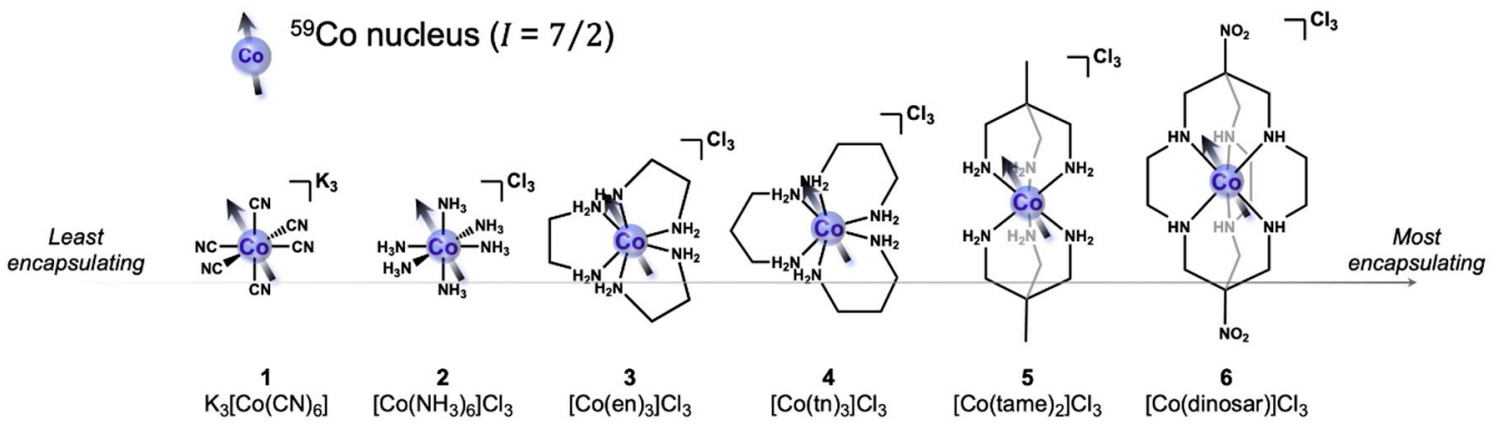

Figure 1. Chemical structure series of low-spin octahedral cobalt(III) complexes. Complexes 2-6 make up the series of progressively encapsulated ${ }^{59} \mathrm{Co}$ nuclei by greater degrees of chelation in a common $\mathrm{Co}-\mathrm{N}_{6}$ coordination environment. Arrows represent the $I={ }^{7} / 2$ nuclear spin of the ${ }^{59} \mathrm{Co}$ nuclei in each complex. Hydrogens bound to carbons are omitted for clarity.

\section{Materials and Methods}

\subsection{General Considerations}

Compounds utilized in this study were either purchased from commercial chemical vendors and used as received (1 and $\mathbf{2}$ ) or synthesized according previously reported literature preparations (3-6) [20-24].

\subsection{Variable-Temperature ${ }^{59} \mathrm{Co}-\mathrm{NMR}$ Spectroscopy}

Samples of all measured compounds were made as $0.7 \mathrm{~mL}$ volumes of $30 \mathrm{mM}$ concentrations in protiated distilled water. Spectroscopic measurements were made at $118 \mathrm{MHz}\left({ }^{59} \mathrm{Co}\right)$ using an Agilent Unity INOVA $500 \mathrm{MHz}\left({ }^{1} \mathrm{H}\right)$ spectrometer at a field strength of $11.74 \mathrm{~T}$ with a $5 \mathrm{~mm}$ BB NMR probe. Before any data collection, standard shims, deuterium locking, and probe tuning were made on $1 \mathrm{M}$ sample of $\mathrm{K}_{3}\left[\mathrm{Co}(\mathrm{CN})_{6}\right]$ in $\mathrm{D}_{2} \mathrm{O}$, the ${ }^{59} \mathrm{Co}-\mathrm{NMR}$ reference standard. During ${ }^{59} \mathrm{Co}-\mathrm{NMR}$ experiments, data were collected in the absence of shimming and locking due to field stability of the instrument. Each sample was measured across a temperature range of $10-60{ }^{\circ} \mathrm{C}$ in $10^{\circ} \mathrm{C}$ intervals. For each 
regulated temperature interval, samples were allowed to thermally equilibrate for $15 \mathrm{~min}$ before the probe was tuned for each pulse experiment.

\subsection{Variable-Temperature ${ }^{59}$ Co Inversion Recovery and CPMG Experiments}

Inversion recovery experiments were made on each sample across a temperature range of $10-60{ }^{\circ} \mathrm{C}$ in $10^{\circ} \mathrm{C}$ intervals upon thermal equilibration. Inversion recovery data were acquired from $180^{\circ}-\tau-90^{\circ}$ pulse sequence experiments with $180^{\circ}$ and $90^{\circ}$ pulse lengths set at 22.4 and $11.2 \mu$ s, respectively. Pulse delay lengths $\tau$ were set by exponentially incremented time intervals relative to previously reported room temperature $T_{1}$ values of each compound [19]. Similarly, CPMG (Carr-Purcell-Meiboom-Gill) pulse sequence experiments were made on each sample across a temperature range of $10-60{ }^{\circ} \mathrm{C}$ in $10{ }^{\circ} \mathrm{C}$ increments $[25,26]$. CPMG data were acquired from $90^{\circ}-\left(\tau-180^{\circ}-\tau\right)_{n}$ spin echo pulse sequence experiments with $180^{\circ}$ and $90^{\circ}$ pulse lengths identical to the corresponding inversion recovery parameters.

\subsection{Computation of ${ }^{59} \mathrm{Co}$ Quadrupolar Coupling Constants}

Computational analyses were completed for the $\mathrm{Co}-\mathrm{N}_{6}$ encapsulation series (2-6) by structural optimizations over a range of temperatures. Temperature-specific optimizations were assisted by previous extended X-ray absorption fine-structure (EXAFS) characterization by fixing $\mathrm{Co}-\mathrm{N}$ distances according to experimentally determined metal-ligand bond lengths to the three temperatures utilized in the EXAFS study, i.e., 13,35 , and $57^{\circ} \mathrm{C}$ [27]. The remainder of the structure was allowed to optimize freely about the fixed $\mathrm{Co}-\mathrm{N}_{6}$ coordination sphere using the Gaussian 16 [28] electronic structure package. Electronic properties calculations were then performed using Orca 4.11 [29] to predict the quadrupolar coupling constant parameter $\left(e^{2} q Q\right)$ of the temperature-specific optimized structures.

\section{Results}

The first temperature-dependent ${ }^{59} \mathrm{Co}$ nuclear spin property we investigated was the spin-lattice, or $T_{1}$, relaxation time. Variable-temperature inversion recovery experiments were performed for 1-6 over a $10-60{ }^{\circ} \mathrm{C}$ temperature range. At each temperature, an initially inverted ${ }^{59} \mathrm{Co}-\mathrm{NMR}$ peak was observed and intensity was recovered as a function of increasing delay time following the inverting $\pi$ pulse. Figure 2a shows the resulting recovery curves of 4 obtained from these pulsed experiments at different temperatures. Additional inversion recovery curves are available in the supplementary information (Figures S1-S6). The fitted inversion recovery data for 1-6 reveal lengthening of $T_{1}$ with increasing temperature. The observed ranges of $T_{1}$ span from 112.9(9) to 167(2) $\mathrm{ms}$ for $\mathbf{1}, 39.8(2)$ to $57(1)$ $\mathrm{ms}$ for $2,6.07(3)$ to $17.25(9) \mathrm{ms}$ for 3, 1.79(5) to 6.6(1) $\mathrm{ms}$ for 4, 243(4) to 753(3) $\mu \mathrm{s}$ for 5, and 264(7) to 682(2) $\mu$ s for 6 (Figure 2c). The largest absolute change in $T_{1}$ over this temperature range is exhibited by $\mathbf{1}\left(\Delta T_{1}=54(3) \mathrm{ms}\right)$, while the smallest difference occurs for $\mathbf{6}\left(\Delta T_{1}=408(9) \mu \mathrm{s}\right)$. Between the minimum and maximum values of $\mathbf{1}$ and $\mathbf{6}$, absolute changes in $\Delta T_{1}$ for $\mathbf{2}-\mathbf{5}$ are $17(1) \mathrm{ms}, 11.2(1) \mathrm{ms}, 4.8(2) \mathrm{ms}$, and $511(7) \mu \mathrm{s}$, respectively. The general magnitudes of these values are consistent with previous ${ }^{59} \mathrm{Co}$ relaxation data on structurally similar cobalt systems [30-33].

For the purpose of comparison, it is useful to define relative changes in $T_{1}$ for each complex since absolute differences $\Delta T_{1}$, as above, heavily weight molecules with long $T_{1}$ times. As a result, the use of logarithmic scales of $T_{1}$ with temperature are necessary to show a clear comparison of $\Delta T_{1}$ between 1-6 (Figure S7). In the following discussion, we express a comparative degree of change in $T_{1}$ between 10 to $60^{\circ} \mathrm{C}$ as a percentage difference divided by the $50^{\circ} \mathrm{C}$ window. For example, the $\Delta T_{1}$ of 1 over 10 to $60^{\circ} \mathrm{C}$ is approximately $54 \mathrm{~ms}$. This value corresponds to a $48.2 \%$ increase in $T_{1}$ from $112.9 \mathrm{~ms}$ $\left(10{ }^{\circ} \mathrm{C}\right.$ ) over the $50{ }^{\circ} \mathrm{C}$ window, thus quantitated by $0.96(6) \% T_{1} /{ }^{\circ} \mathrm{C}$. Similarly, the other relative $\Delta T_{1} / \Delta T$ sensitivities are $0.86(6), 3.68(6), 5.3(3), 4.2(1)$, and $3.2(2) \% T_{1} /{ }^{\circ} \mathrm{C}$ for $2-6$, respectively. Figure $2 \mathrm{~b}$ depicts the relative magnitudes of these values for all complexes over the $10-60{ }^{\circ} \mathrm{C}$ temperature window on a logarithmic scale. Owing to the potential utility of relaxation in modern biomedical imaging techniques, we highlight the aforementioned values of $\Delta T_{1} / \Delta T$ within the biologically relevant domain 
of $30-40{ }^{\circ} \mathrm{C}$ at $0.65(1), 0.70(1), 2.35(2), 2.98(9), 2.24(3)$, and $2.12(2) \% \mathrm{~T}_{1} /{ }^{\circ} \mathrm{C}$ for $1-6$, respectively (Figure $2 \mathrm{c}$ ). These values follow the same general trend as with the $10-60{ }^{\circ} \mathrm{C}$ window, though the changes in magnitude differ slightly.
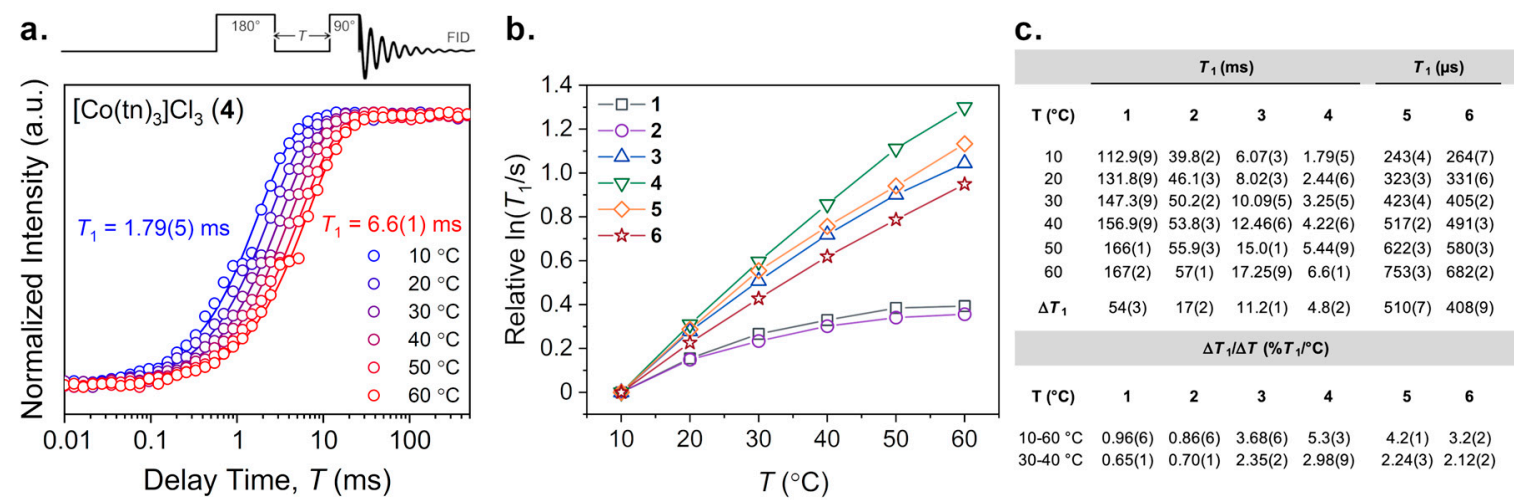

Figure 2. (a) Experimental variable-temperature $\left(10-60^{\circ} \mathrm{C}\right)$ inversion recovery measurements (circles) with exponential recovery fits (traces) for $\left[\mathrm{Co}(\mathrm{tn})_{3}\right] \mathrm{Cl}_{3}(4)$ on logarithmic scale. Temperature-specific $T_{1}$ values were extracted from exponential decay fits. The general pulse sequence for the inversion recovery experiment is depicted. (b) Variable-temperature $T_{1}$ plots of 1-6 on logarithmic scale showing relative changes. Error bars are within the width of the data points. Traces are guides for the eye. (c) Temperature-specific $T_{1}$ spin-lattice relaxation times with error for 1-6 from $10-60{ }^{\circ} \mathrm{C}$ with absolute values of $\Delta T_{1}$ and relative values of $\Delta T_{1} / \Delta T$ temperature sensitivities.

Notably, $\mathbf{4}$ shows the greatest change for both temperature windows, and $\mathbf{1}$ and $\mathbf{2}$ show the smallest relative increase in $T_{1}$. However, the relation between $T_{1}$ and $T$ show varying degrees of temperature linearity across the series. $T_{1}$ is expected to show a linear temperature dependence if the quadrupolar mechanism is operative. A high degree of linearity is shown by the $D_{3}$-symmetric molecules of the series, 3-6. For these complexes, quadrupolar relaxation is expected due to the interaction between the electric quadrupolar moment and the lower-symmetry electric field gradient at the ${ }^{59}$ Co nucleus (relative to $O_{\mathrm{h}} \mathbf{1}$ and 2). However, the non-linear relaxation behaviors of $\mathbf{1}$ and $\mathbf{2}$ suggest different operative relaxation processes of the central ${ }^{59}$ Co nucleus [30,34]. For these complexes, curvature in the plots of $\ln \left(T_{1} / \mathrm{s}\right)$ vs. $T\left({ }^{\circ} \mathrm{C}\right)$ (Figure $2 \mathrm{~b}$ ) show a gradual decline with increasing temperature, indicative of another contributing relaxation mechanism. The spin-rotation relaxation mechanism is known to contribute to relaxation in similar $\mathrm{O}_{\mathrm{h}}{ }^{59} \mathrm{Co}$ complexes, $[30,31]$ thus is the likely origin of the non-linear temperature dependence in $\mathbf{1}$ and $\mathbf{2}$.

The second temperature-dependent nuclear spin property we investigated was $T_{2}$. Variable-temperature CPMG experiments were performed over a $10-60{ }^{\circ} \mathrm{C}$ temperature range for on 1-3, and a $30-60{ }^{\circ} \mathrm{C}$ range for 4 to collect $T_{2}$ values. At each temperature measurement, a ${ }^{59} \mathrm{Co}$ NMR peak was observed with an intensity that decayed as a function of increasing number of $\pi$ pulses. Figures S8-S11 show the resulting decay curves of the studied complexes and $T_{2}$ times were determined from exponential fits of the decay. Similar to the temperature-dependent $T_{1}$ behaviors, $T_{2}$ increases with increasing temperature for 1-4. Figure 3 a shows the relaxation trends for 1-4 over the $50{ }^{\circ} \mathrm{C}$ window. Unfortunately, due to instrumental limitations, we were not able to collect $T_{2}$ values for 4 at 10 and $20^{\circ} \mathrm{C}$, nor for 5 and 6 at any temperature between $10-60{ }^{\circ} \mathrm{C}$. Pulse delay times for CPMG experiments on complexes with relatively low $T_{2}$ values approached the same timescales as the pulse durations (on the order of 10-20 $\mu$ s). Thus, CPMG data could not be collected for 5 and 6 , which are likely to have even shorter $T_{2}$ times than 4 at $30{ }^{\circ} \mathrm{C}$ (the shortest experimentally determined $T_{2}$ value). For 1-4, the observed range of $T_{2}$ times span from 102(3) to 132(3) ms for 1, 9(1) to 32(6) $\mathrm{ms}$ for 2 , and 3.1(3) to $12.0(7) \mathrm{ms}$ for 3 (Figure 3c). The largest absolute change in $\mathrm{T}_{2}$ over a $10-60^{\circ} \mathrm{C}$ temperature range is exhibited by $\mathbf{1}\left(\Delta T_{2}=30(6) \mathrm{ms}\right)$, followed by decreasing values of $\Delta T_{2}$ at $23(7) \mathrm{ms}$ 
for 2, and 9(1) $\mathrm{ms}$ for 3. Between $30-60^{\circ} \mathrm{C}, \mathrm{T}_{2}$ for 4 was measured from $2.6(3)$ to $4.6(5) \mathrm{ms}$ with an absolute $\Delta T_{2}$ of $2.0(8) \mathrm{ms}$. The increases in $T_{2}$ over the studied range are expressed as $\Delta T_{2} / \Delta T$ by $0.6(1)$, $5(2)$, and $6(1) \% T_{2} /{ }^{\circ} \mathrm{C}$ over $10-60{ }^{\circ} \mathrm{C}$ for $1-3$, respectively, while an increase of $3(1) \% T_{2} /{ }^{\circ} \mathrm{C}$ is shown for 4 over $30-60{ }^{\circ} \mathrm{C}$.

a.

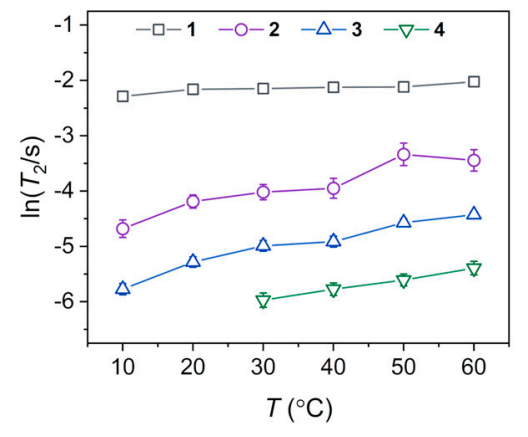

b.

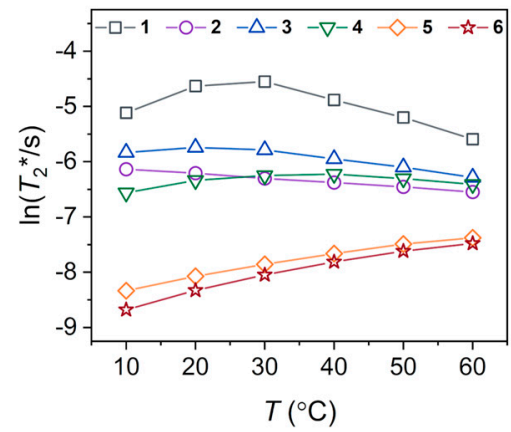

c.

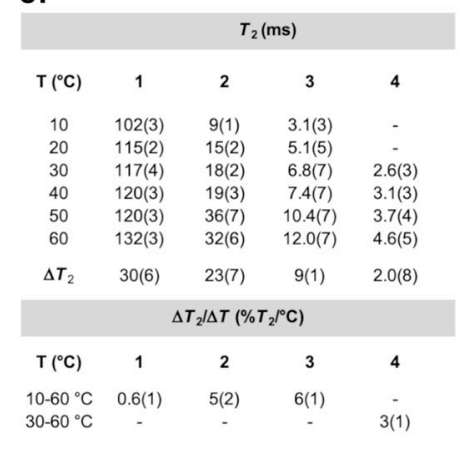

Figure 3. (a) Variable-temperature $T_{2}$ plots of 1-4 on logarithmic scale showing relative changes in $T_{2}$ spin-spin relaxation times. Error bars for $\mathrm{K}_{3}\left[\mathrm{Co}(\mathrm{CN})_{6}\right](\mathbf{1})$ are within the width of the data points. Traces in both plots are mean to guide the eye. (b) Variable-temperature $T_{2}{ }^{*}$ trends from linewidth analyses of 1-6 from 1D ${ }^{59}$ Co NMR spectra. (c) Temperature-specific $T_{2}$ spin-spin relaxation times with error for 1-4 with absolute values of $\Delta T_{2}$ and relative values of $\Delta T_{2} / \Delta T$ temperature sensitivities.

As an additional method of comparing the variation in ${ }^{59}$ Co nuclear spin properties of 1-6, we investigated the dephasing time, or $T_{2}{ }^{*}$, a relaxation time analogous to $T_{2}$ above. $T_{2}{ }^{*}$ can be extracted from the temperature-dependent NMR linewidths through the relationship $T_{2}{ }^{*}=1 /(2 \pi \Delta v)$ where $\Delta v(\mathrm{~Hz})$ is the full width at half the maximum height (FWHM) of the ${ }^{59}$ Co-NMR peak. This method enables a complete comparison of 1-6, in contrast to the CPMG experiments. Figure 3b shows the temperature-dependent trends in $T_{2}{ }^{*}$ for all complexes over the $10-60{ }^{\circ} \mathrm{C}$ range. Complexes $\mathbf{1}, 3$, and 4 all show increasing $T_{2}{ }^{*}$ with increasing temperature up to a maximum, then begin to decrease with further increasing temperature. The maxima occur near 30,20 , and $40^{\circ} \mathrm{C}$ for $\mathbf{1}, 3$, and 4 , respectively. In contrast, complex 2 shows a continual decline in $T_{2}{ }^{*}$ over the studied temperature range, while 5 and 6 both exhibit linear increases in $T_{2}^{*}$. The absolute changes in $\Delta T_{2}^{*}$ over $10-60{ }^{\circ} \mathrm{C}$ are $-2.27,-0.73,-1.06,0.24,0.39$, and $0.40 \mathrm{~ms}$ for $\mathbf{1}-6$, respectively (Table S1). This trend is reflected in the smaller, biologically relevant $30-40{ }^{\circ} \mathrm{C}$ window, where absolute $\Delta T_{2}{ }^{*}$ values are $-2.99,-0.13$, $-0.46,0.05,0.08$, and $0.08 \mathrm{~ms}$. As with $\Delta T_{1}$ and $\Delta T_{2}$, the absolute difference in timescales heavily weights complexes with already long $T_{2}{ }^{*}$ values. The relative changes according to $\Delta T_{2}^{*} / \Delta T$, which here describe essentially the temperature dependence of the spectral linewidth, are $-0.76,-0.67,-0.72$, $0.33,3.21$, and $4.64 \% T_{2} *{ }^{\circ} \mathrm{C}$ for $1-6$, respectively. The largest increase in $T_{2}{ }^{*}$ is shown by 6 , with 5 showing the second largest increase. This trend is reflected in the narrowing linewidths observed in the ${ }^{59}$ Co NMR spectra as a function of increasing temperature.

To assist in understanding the relaxation time data, we computed values of the quadrupolar coupling constant parameter $\left(e^{2} q Q\right)$ for the Co- $\mathrm{N}_{6}$ encapsulation series (2-6) at different temperatures within the $10-60{ }^{\circ} \mathrm{C}$ window. Predictions of $e^{2} q Q$ were completed from partially optimized, variable-temperature structures following analyses from extended $X$-ray absorption fine-structure (EXAFS) spectroscopy [27]. Values of $e^{2} q Q$ computed for these structures range from -1.861 to $-1.910 \mathrm{MHz}$ for 2, 2.441 to 2.392 for 3, 1.088 to $0.893 \mathrm{MHz}$ for 4, 8.165 to $8.156 \mathrm{MHz}$ for 5, and 6.879 to $6.834 \mathrm{MHz}$ for 6 (Figure 4). The smallest values of $e^{2} q Q$ are found for the smaller complexes (2-4) reflecting higher symmetries in molecular structure, relative to the larger, more encapsulating $D_{3}$ structures (5 and 6) showing the largest values of $e^{2} q Q$ in the series. 
a.

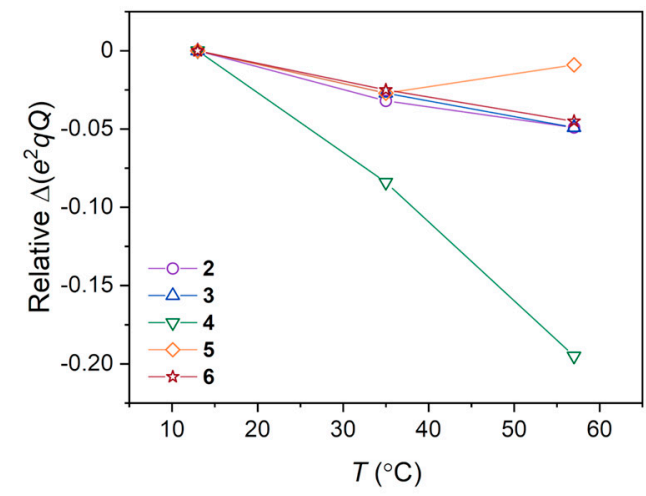

b.

\begin{tabular}{ccccc} 
& \multicolumn{3}{c}{$e^{2} q Q(\mathrm{MHz})$} & $\Delta\left(e^{2} q Q\right)$ \\
\cline { 2 - 5 } Complex & $\mathbf{1 3}{ }^{\circ} \mathrm{C}$ & $\mathbf{3 5}{ }^{\circ} \mathrm{C}$ & $\mathbf{5 7}{ }^{\circ} \mathrm{C}$ & \\
$\mathbf{2}$ & -1.861 & -1.893 & -1.910 & -0.049 \\
$\mathbf{3}$ & 2.441 & 2.414 & 2.392 & -0.049 \\
$\mathbf{4}$ & 1.088 & 1.004 & 0.893 & -0.195 \\
$\mathbf{5}$ & 8.165 & 8.138 & 8.156 & -0.009 \\
$\mathbf{6}$ & 6.879 & 6.854 & 6.834 & -0.045 \\
& & & &
\end{tabular}

Figure 4. (a) Trends in predicted quadrupolar coupling parameters, $e^{2} q Q$, from variable-temperature predicted structures of 2-6. (b) Temperature-specific quadrupolar coupling parameters at each temperature-specific structure and $\Delta e^{2} q Q$ over the $\sim 50{ }^{\circ} \mathrm{C}$ range.

The differences in $e^{2} q Q$ by temperature-driven structure vary in scale, but all decrease with increasing temperature (Figure 4). Values of $\Delta e^{2} q Q$ for $\mathbf{2}-\mathbf{6}$ are found to be $-0.049,-0.049,-0.195$, -0.009 , and $-0.045 \mathrm{MHz}$, respectively. Of these predicted values, the greatest change is found for 4 followed by $\mathbf{2}$ and 3 , then $\mathbf{6}$ and 5 . Importantly, the largest $\Delta e^{2} q Q$ is exhibited by 4 which also shows the largest $\Delta T_{1} / \Delta T$ value. Conversely, the encapsulated $D_{3}$ structures of 5 and $\mathbf{6}$ possess the highest magnitudes of $e^{2} q Q$ between 8.156 to $8.165 \mathrm{MHz}$ and 6.834 to $6.879 \mathrm{MHz}$, respectively, but show the least change by $\Delta e^{2} q Q$.

\section{Discussion}

Spin-lattice relaxation of the ${ }^{59} \mathrm{Co}$ nucleus is primarily attributed to the electric quadrupolar coupling interaction [30-32], which is dictated by the symmetry and structure of a given ligand shell. Evaluation of $T_{1}$ via Arrhenius analyses of 1-6 elucidate the extent to which this is true. In principle, a higher linearity of $\ln \left(T_{1}\right)$ vs. $1 / T\left(10^{3} \mathrm{~K}^{-1}\right)$ depicted in Figure 5 indicates the contribution of a single relaxation process in governing $T_{1}$. A slightly curved temperature dependence is observed for $O_{\mathrm{h}}$ 1 and 2, as evidenced by the lower $\mathrm{R}^{2}$ values (0.91) to linear regression. Conversely, highly linear trends are observed for the more $D_{3}$-symmetry 3-6, with $R^{2}$ values of 0.99 . For this latter series of four complexes, an activation energy, $E_{\mathrm{a}}$, can be extracted from these linear fits to the Arrhenius equation, $1 / T_{1}=\mathrm{A} \exp \left(-E_{\mathrm{a}} / \mathrm{R} T\right)$, where $\mathrm{A}$ is a preexponential factor, $\mathrm{R}$ is the ideal gas constant, and $T$ is absolute temperature (Table S2). Here, $E_{\mathrm{a}}$ describes the activation energy to molecular tumbling, and a lower $E_{\mathrm{a}}$ suggests more facile motion in solution [30,35,36]. Activation energies for $\mathbf{3 - 6}$ are found to be 16.4(5), 20.6(3), 17.6(5), and 14.9(1) kJ/mol, respectively (1.37(4), 1.72(3), 1.47(4), and 1.24(1) $\times$ $10^{3} \mathrm{~cm}^{-1}$, respectively). Values of $E_{\mathrm{a}}$ increase from $\mathbf{6}<\mathbf{3}<\mathbf{5}<\mathbf{4}$, reflecting the same trend in $\Delta T_{1} / \Delta T$. Notably, the moderately encapsulated complex 4 shows the highest barrier to rotation and also the highest $\Delta T_{1} / \Delta T$. If the spin-lattice relaxation is expected to be driven by motional changes dependent on molecular mass, then the observed trend in $\Delta T_{1} / \Delta T$ cannot be strictly reasoned by changes in a temperature-dependent correlation time, $\tau_{\mathrm{c}}$ (Figure S12 and Table S3). If the former were true, then the larger complexes $\mathbf{5}$ and $\mathbf{6}$ would be expected to have higher activation energies than that shown for $\mathbf{4}$, an outcome that would be reflected by a longer $\tau_{c}$ in solution. In fact, they show shorter $\tau_{c}$ values, despite having larger ligand scaffolds. Thus, we conclude that the standard mechanisms for describing temperature-dependent relaxation, which principally stem from changes in correlation time, do not solely account for the observed changes here. 


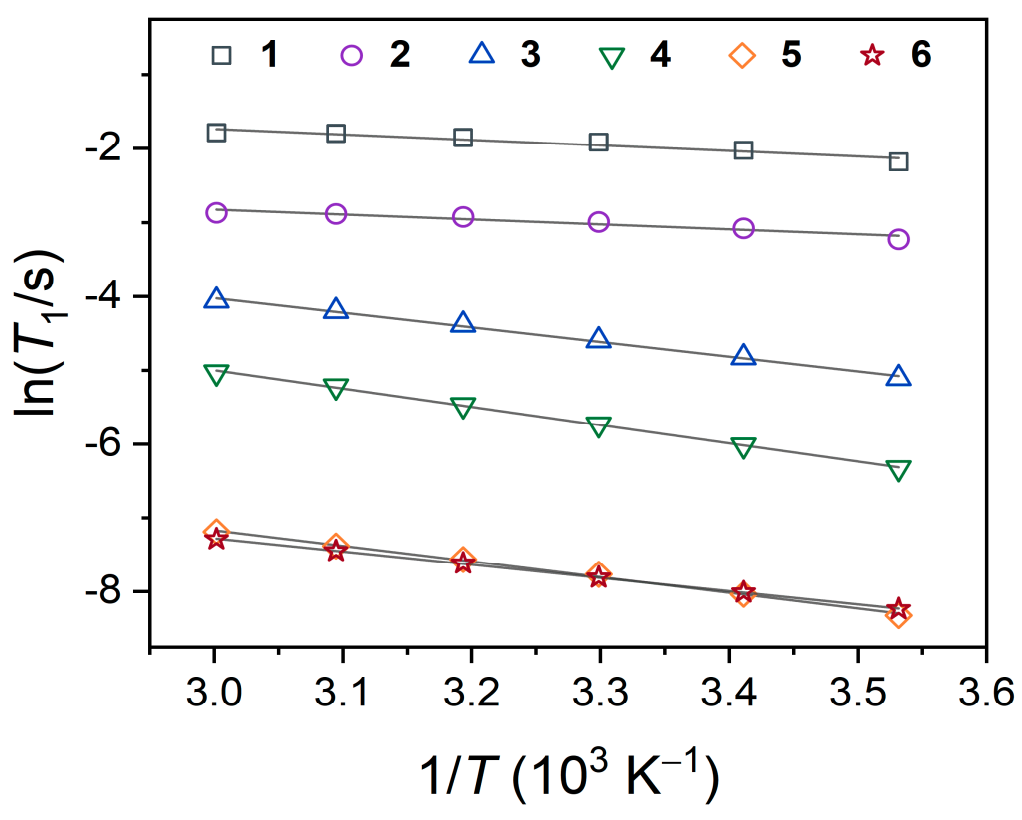

Figure 5. Arrhenius plots of variable-temperature $T_{1}$ relaxation. Solid grey lines indicate linear regressions for 1-6. Values of $\mathrm{R}^{2}$ from each fit (Table S2) are used to determine temperature linearity for each complex.

We instead propose that these changes in motion synergize with changes in the local symmetry of the ${ }^{59}$ Co nucleus to produce the observed trends in $\Delta T_{1} / \Delta T$, especially in the series of $D_{3}$ structures. Previous studies of 3-6 revealed $\sim 0.007 \AA$ changes in Co-N bond distances per ${ }^{\circ} \mathrm{C}$ over the $50{ }^{\circ} \mathrm{C}$ temperature range of our investigations here [27]. These changes in bond distances were also accompanied by changes in symmetry of the coordination geometry through changes in $\mathrm{N}-\mathrm{Co}-\mathrm{N}$ angles. As a result of these changes in symmetry, we find in our calculations here that the quadrupolar coupling constants decrease with increasing temperature with a magnitude that trends as $\mathbf{4}>\mathbf{3}>\mathbf{6}>\mathbf{5}$ (Figure 4). The trend in $\Delta e^{2} q Q$ does not completely correlate to the trend in relaxation across the series, hence our suggestion that motion is also important. However, complex 4 shows both the greatest value of $\Delta e^{2} q Q$ at $-0.194 \mathrm{MHz}$, and the highest $\Delta T_{1} / \Delta T$ at $5.3(3) \% T_{1} / \Delta T$ over the $50{ }^{\circ} \mathrm{C}$ window.

The nearly equivalent values of $T_{1}$ and $T_{2}$ suggest that $T_{2}$ is limited by $T_{1}$, and, as such, $T_{2}$ is also expected to be impacted by the quadrupolar coupling. However, the temperature dependence of $T_{2}$ does not follow $T_{1}$. Owing to the large temperature dependence of the ${ }^{59}$ Co chemical shift, we attribute this discrepancy to slight differences in resonance frequency by small temperature fluctuations which do not affect $T_{1}$ as strongly as $T_{2}$ [37]. We further highlight that the fast time scales of $T_{2}$ for 5 and 6 are beyond the limits of the instrumentation. Hence, it would be challenging to utilize $T_{2}$ as a thermometric parameter for these species. In that light, the temperature dependence of the ${ }^{59} \mathrm{Co}$ linewidth appears more favorable for thermometry in complexes of greater encapsulation (and thus most chemically stable) owing to the linearity of $\Delta T_{2}^{*} / \Delta T$ in the tridentate and encapsulated species 5 and 6. Finally, we note that the values of $T_{2}{ }^{*}$ obtained here are likely lower bounds for this parameter, as temperature inhomogeneities in the instrument cavity (by even a fraction of $1^{\circ} \mathrm{C}$ ) will broaden the signal independent of $T_{2}{ }^{*}$.

The above analyses suggest three important points for the development of ${ }^{59}$ Co spin-based probes for quadrupolar-driven relaxation thermometry. Firstly, we note the importance of chelating or macrocyclic ligands, as 3-6 exhibited mostly quadrupolar relaxation, which is likely driven by the $D_{3}$-directing nature of these ligands. Secondly, we see that enabling a higher $\Delta T_{1} / \Delta T$ is largely dependent on whether the species possesses a strong temperature dependence of the quadrupolar coupling constant, not necessarily the magnitude of constant itself. Complex 4 exemplifies this point. Finally, third, the range of computed $e^{2} q Q$ and $\Delta e^{2} q Q$ imply a tunable quadrupolar coupling 
interaction through temperature-driven structures. It is worth noting that this is, to the best of our knowledge, the first argument for this effect in governing thermometry by relaxation. Moreover, in this context, the most-encapsulated structures, 5 and $\mathbf{6}$, both show the lowest $\Delta e^{2} q Q$ values, compared to the structures of 3 and $\mathbf{4}$ with lesser denticity. This effect may be rationalized by a hindered variation in the symmetry of the structure due to the relative interconnectivity of the individual $\mathrm{N}$ donor atoms. Indeed, EXAFS analyses suggest that 4 exhibits the greatest transition towards $\mathrm{O}_{\mathrm{h}}$ symmetry with increasing temperature when 3, 5, and 6 all deviate toward $D_{3}$ symmetry [27]. This subtle difference in temperature-dependent structure is likely an important point toward designing future ${ }^{59}$ Co NMR thermometers.

\section{Conclusions}

We report a collection of temperature-dependent relaxation dynamic studies on a series of progressively encapsulated cobalt(III) complexes. The foregoing temperature-dependent data underline the fact that structure plays a vital role in controlling relaxation thermometry for the ${ }^{59}$ Co nucleus, but the coarse design principle of "encapsulation" does not solely govern the temperature dependence of $T_{1}$ nor $T_{2}^{*}$. Relaxation times are found to be largely determined by the quadrupolar coupling interaction for the $D_{3}$ complexes and a combination of quadrupolar and spin-rotation mechanisms for the $O_{\mathrm{h}}$ species ( $\mathbf{1}$ and 2 ). The chelated complex 4 has the largest relative increase in $T_{1}$ as a function of its decrease in quadrupolar coupling, as mediated by a temperature-driven structure. We also found that encapsulated $\mathrm{Co}-\mathrm{N}_{6}$ species, demonstrated by 5 and $\mathbf{6}$, are potentially promising thermometric structures by linear $T_{2}{ }^{*}$ temperature dependencies. These factors thus provide a foundation for future studies of tuning temperature-dependent nuclear spin relaxation processes in $\mathrm{Co}(\mathrm{III})$ complexes.

Supplementary Materials: The following are available online at http://www.mdpi.com/2312-7481/6/4/58/s1, Figure S1: Variable-temperature inversion recovery fits of 1, Figure S2: Variable-temperature inversion recovery fits of 2, Figure S3: Variable-temperature inversion recovery fits of 3, Figure S4: Variable-temperature inversion recovery fits of 4, Figure S5: Variable-temperature inversion recovery fits of 5, Figure S6: Variable-temperature inversion recovery fits of 6, Figure S7: $T_{1}$ trend analysis $\ln \left(T_{1}\right)$ vs. $T\left({ }^{\circ} \mathrm{C}\right)$ of 1-6, Figure S8: Variable-temperature CPMG fits of 4 from $30-60{ }^{\circ} \mathrm{C}$, Figure S9: Variable-temperature CPMG fits of 1 from $10-60{ }^{\circ} \mathrm{C}$, Figure S10: Variable-temperature CPMG fits of 2 from $10-60{ }^{\circ} \mathrm{C}$, Figure S11: Variable-temperature CPMG fits of 3 from 10-60 ${ }^{\circ} \mathrm{C}$, Figure S12: Variable-temperature correlation times of 2-6, Table S1: Variable-temperature ${ }^{59}$ Co $T_{2}{ }^{*}$ values and linewidth fit values, Table S2: Linear trend fit parameters for $\ln \left(T_{1}\right)$ vs $1 / T\left(10^{3} \mathrm{~K}^{-1}\right)$ of $\mathbf{1 - 6}$, Table S3: Calculated variable-temperature correlation times of 2-6, Table S4: Computed structure of 3 at $13^{\circ} \mathrm{C}$, Table S5: Computed structure of 3 at $35^{\circ} \mathrm{C}$, Table S6: Computed structure of 3 at $57^{\circ} \mathrm{C}$, Table S7: Computed structure of 4 at $13{ }^{\circ} \mathrm{C}$, Table S8: Computed structure of 4 at $35^{\circ} \mathrm{C}$, Table S9: Computed structure of 4 at $57{ }^{\circ} \mathrm{C}$, Table S10: Computed structure of 5 at $13{ }^{\circ} \mathrm{C}$, Table S11: Computed structure of 5 at $35^{\circ} \mathrm{C}$, Table S12: Computed structure of $\mathbf{5}$ at $57^{\circ} \mathrm{C}$, Table S13: Computed structure of 6 at $13{ }^{\circ} \mathrm{C}$, Table S14: Computed structure of 6 at $35^{\circ} \mathrm{C}$, Table S15: Computed structure of 6 at $57^{\circ} \mathrm{C}$.

Author Contributions: T.M.O., A.K.R., and J.M.Z. conceived of the experiments, T.M.O. and S.H.J. collected all reported experimental and computational data. All authors were involved in the composition of the manuscript. All authors have read and agreed to the published version of the manuscript.

Funding: This research was performed with the support of Colorado State University (CSU) and the NIH (R21-EB027293). NMR experiments were performed on an instrument at the CSU Analytical Resources Core, which is supported by an NIH-SIG award (1S10OD021814-01) and the CSU-CORES Program. Computational resources are enabled by the Catalysis Collaboratory for Light-activated Earth Abundant Reagents (C-CLEAR), which is supported by the National Science Foundation (NSF) and the Environmental Protection Agency through the Networks for Sustainable Molecular Design and Synthesis (CHE-1339674) at Colorado State University, Fort Collins. S.H.J. acknowledges the Colorado Chapter of the ARCS Foundation for their continued support.

Acknowledgments: We acknowledge Z. Cleveland and C. Rithner for useful discussions and experimental assistance.

Conflicts of Interest: There are no conflict of interest to report in this work. 


\section{References}

1. Sotoma, S.; Epperla, C.P.; Chang, H.-C. Diamond Nanothermometry. ChemNanoMat 2018, 4, 15-27. [CrossRef]

2. Toyli, D.M.; de las Casas, C.F.; Christle, D.J.; Dobrovitski, V.V.; Awschalom, D.D. Fluorescence thermometry enhanced by the quantum coherence of single spins in diamond. Proc. Natl. Acad. Sci. USA 2013, 110, 8417-8421. [CrossRef] [PubMed]

3. Hui, Y.Y.; Chen, O.Y.; Azuma, T.; Chang, B.-M.; Hsieh, F.-J.; Chang, H.-C. All-Optical Thermometry with Nitrogen-Vacancy Centers in Nanodiamond-Embedded Polymer Films. J. Phys. Chem. C 2019, 123, 15366-15374. [CrossRef]

4. Thiele, S.; Balestro, F.; Ballou, R.; Klyatskaya, S.; Ruben, M.; Wernsdorfer, W. Electrically driven nuclear spin resonance in single-molecule magnets. Science 2014, 344, 1135-1138. [CrossRef]

5. Gershenfeld, N.A.; Chuang, I.L. Bulk Spin-Resonance Quantum Computation. Science 1997, 275, 350-356. [CrossRef]

6. Havel, T.F.; Cory, D.G.; Lloyd, S.; Boulant, N.; Fortunato, E.M.; Pravia, M.A.; Teklemariam, G.; Weinstein, Y.S.; Bhattacharyya, A.; Hou, J. Quantum information processing by nuclear magnetic resonance spectroscopy. Am. J. Phys. 2002, 70, 345-362. [CrossRef]

7. Vandersypen, L.M.; Steffen, M.; Breyta, G.; Yannoni, C.S.; Sherwood, M.H.; Chuang, I.L. Experimental realization of Shor's quantum factoring algorithm using nuclear magnetic resonance. Nature 2001, 414, 883-887. [CrossRef]

8. Brace, C. Thermal Tumor Ablation in Clinical Use. IEEE Pulse 2011, 2, 28-38. [CrossRef]

9. Tseng, H.; Lin, S.-E.; Chang, Y.-L.; Chen, M.-H.; Hung, S.-H. Determining the critical effective temperature and heat dispersal pattern in monopolar radiofrequency ablation using temperature-time integration. Exp. Ther. Med. 2016, 11, 763-768. [CrossRef]

10. Yuan, J.; Mei, C.-S.; Panych, L.P.; McDannold, N.J.; Madore, B. Towards fast and accurate temperature mapping with proton resonance frequency-based MR thermometry. Quant. Imaging Med. Surg. 2012, 2, 21-32.

11. Van Rhoon, G.C.; Wust, P. Introduction: Non-invasive thermometry for thermotherapy. Int. J. Hyperth. 2005, 21, 489-495. [CrossRef]

12. Levy, G.C.; Terry Bailey, J.; Wright, D.A. A sensitive NMR thermometer for multinuclei FT NMR. J. Magn. Reson. 1980, 37, 353-356. [CrossRef]

13. Bornais, J.; Brownstein, S. A low-temperature thermometer for ${ }^{1} \mathrm{H},{ }^{19} \mathrm{~F}$, and ${ }^{13} \mathrm{C}$. J. Magn. Reson. 1978, 29, 207-211. [CrossRef]

14. Quast, H.; Heubes, M.; Dunger, A.; Limbach, H.-H. A high-precision carbon-13 shift thermometer for the temperature range 100-300 K. J. Magn. Reson. 1998, 134, 236-244. [CrossRef] [PubMed]

15. Zuo, C.S.; Bowers, J.L.; Metz, K.R.; Nosaka, T.; Sherry, A.D.; Clouse, M.E. TmDOTP ${ }^{5-}$ : A substance for NMR temperature measurements in vivo. Magn. Reson. Med. 1996, 36, 955-959. [CrossRef]

16. Sargeson, A.M. Developments in the synthesis and reactivity of encapsulated metal ions. Pure Appl. Chem. 1986, 58, 1511-1522. [CrossRef]

17. Liu, S.; Li, D.; Huang, C.-W.; Yap, L.-P.; Park, R.; Shan, H.; Li, Z.; Conti, P.S. The Efficient Synthesis and Biological Evaluation of Novel Bi-Functionalized Sarcophagine for ${ }^{64} \mathrm{Cu}$ Radiopharmaceuticals. Theranostics 2012, 2, 589-596. [CrossRef]

18. Liu, S.; Li, Z.; Conti, P.S. Development of Multi-Functional Chelators Based on Sarcophagine Cages. Molecules 2014, 19, 4246-4255. [CrossRef]

19. Ozvat, T.M.; Peña, M.E.; Zadrozny, J.M. Influence of ligand encapsulation on cobalt-59 chemical-shift thermometry. Chem. Sci. 2019, 10, 6727-6734. [CrossRef]

20. Krause, R.; Megargel, E. Student synthesis of tris(ethylenediamine)cobalt(III) chloride. J. Chem. Educ. 1976, 53, 667. [CrossRef]

21. Bailar, J.C.; Work, J.B. Some Coördination Compounds of Cobalt Containing Trimethylenediamine and Neopentanediamine. J. Am. Chem. Soc. 1946, 68, 232-235. [CrossRef]

22. Geue, R.J.; Snow, M.R. Structure, conformational analysis and optical activity of a bis(tridentate)cobalt(III) complex. (+)589- $\Delta \lambda \lambda$-Bis[1,1,1-tris(aminomethyl)ethane]cobalt(III) chloride (+)589-(R,R)-tartrate hydrate. Inorg. Chem. 1977, 16, 231-241. [CrossRef] 
23. Qin, C.-J.; James, L.; Chartres, J.D.; Alcock, L.J.; Davis, K.J.; Willis, A.C.; Sargeson, A.M.; Bernhardt, P.V.; Ralph, S.F. An Unusually Flexible Expanded Hexaamine Cage and Its CuII Complexes: Variable Coordination Modes and Incomplete Encapsulation. Inorg. Chem. 2011, 50, 9131-9140. [CrossRef] [PubMed]

24. Bottomley, G.; Clark, I.; Creaser, I.; Engelhardt, L.; Geue, R.; Hagen, K.; Harrowfield, J.; Lawrance, G.; Lay, P.; Sargeson, A.; et al. The Synthesis and Structure of Encapsulating Ligands: Properties of Bicyclic Hexamines. Aust. J. Chem. 1994, 47, 143-179. [CrossRef]

25. Carr, H.Y.; Purcell, E.M. Effects of Diffusion on Free Precession in Nuclear Magnetic Resonance Experiments. Phys. Rev. 1954, 94, 630-638. [CrossRef]

26. Meiboom, S.; Gill, D. Modified Spin-Echo Method for Measuring Nuclear Relaxation Times. Rev. Sci. Instrum. 1958, 29, 688-691. [CrossRef]

27. Ozvat, T.M.; Sterbinsky, G.E.; Campanella, A.J.; Rappé, A.K.; Zadrozny, J.M. EXAFS investigations of temperature-dependent structure in cobalt-59 molecular NMR thermometers. Dalton Trans. 2020. [CrossRef]

28. Frisch, M.J.; Trucks, G.W.; Schlegel, H.B.; Scuseria, G.E.; Robb, M.A.; Cheeseman, J.R.; Scalmani, G.; Barone, V.; Petersson, G.A.; Nakatsuji, H.; et al. Gaussian 16 Rev. C.01; Gaussian, Inc.: Wallingford, CT, USA, 2016.

29. Neese, F. The ORCA program system. WIREs Comput. Mol. Sci. 2012, 2, 73-78. [CrossRef]

30. Kirby, C.W.; Puranda, C.M.; Power, W.P. Cobalt-59 nuclear magnetic relaxation studies of aqueous octahedral cobalt(III) complexes. J. Phys. Chem. 1996, 100, 14618-14624. [CrossRef]

31. Ader, R.; Loewenstein, A. Nuclear magnetic relaxation studies in solutions of symmetric cobalt (III) complexes. J. Magn. Reson. 1969 1971, 5, 248-261. [CrossRef]

32. Chacko, V.P.; Bryant, R.G. Electric field gradient modulation and nuclear magnetic relaxation in hexacyanocobaltate ion. J. Magn. Reson. 1984, 57, 79-84. [CrossRef]

33. Doddrell, D.M.; Bendall, M.R.; Healy, P.C.; Smith, G.; Kennard, C.H.L.; Raston, C.L.; White, A.H. ${ }^{59}$ Co and ${ }^{13} \mathrm{C}$ Nuclear Spin Relaxation Studies in Solutions of Symmetric, Bidentate Cobalt(III) Complexes. On the Mechanism of ${ }^{59}$ Co Spin Relaxation. Crystal Structure Determination of Tris(tropolonato)cobalt(III). Aust. J. Chem. 1979, 32, 1219-1230. [CrossRef]

34. Boeré, R.T.; Kidd, R.G. Rotational Correlation Times in Nuclear Magnetic Relaxation. In Annual Reports on NMR Spectroscopy; Elsevier: Amsterdam, The Netherlands, 1983; Volume 13, pp. 319-385, ISBN 978-0-12-505313-6.

35. Foster, R.J.; Damion, R.A.; Ries, M.E.; Smye, S.W.; McGonagle, D.G.; Binks, D.A.; Radjenovic, A. Imaging of nuclear magnetic resonance spin-lattice relaxation activation energy in cartilage. R. Soc. Open Sci. 2018, 5, 180221. [CrossRef] [PubMed]

36. Rieke, V.; Pauly, K.B. MR Thermometry. J. Magn. Reson. Imaging 2008, 27, 376-390. [CrossRef] [PubMed]

37. Anet, F.A.L.; O'leary, D.J. The shielding tensor part II: Understanding its strange effects on relaxation. Concepts Magn. Reson. 1992, 4, 35-52. [CrossRef]

Publisher's Note: MDPI stays neutral with regard to jurisdictional claims in published maps and institutional affiliations.

(C) 2020 by the authors. Licensee MDPI, Basel, Switzerland. This article is an open access article distributed under the terms and conditions of the Creative Commons Attribution (CC BY) license (http://creativecommons.org/licenses/by/4.0/). 